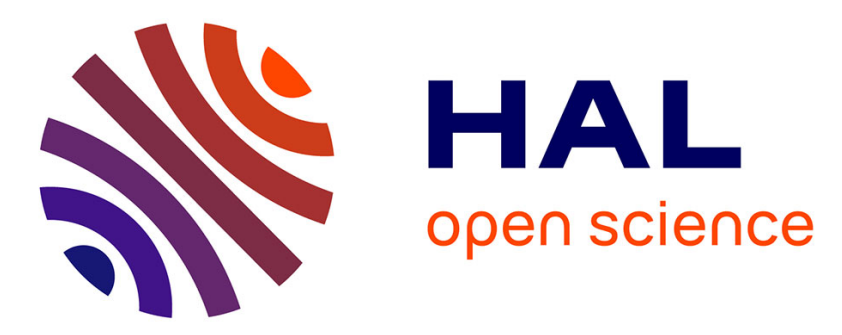

\title{
La Vierge 2020 : Reconstructing a Virtual Concert Performance Through Historic Auralisation of Notre-Dame Cathedral
}

\author{
Brian F. G. Katz, David Poirier-Quinot, Jean-Marc Lyzwa
}

\section{To cite this version:}

Brian F. G. Katz, David Poirier-Quinot, Jean-Marc Lyzwa. La Vierge 2020 : Reconstructing a Virtual Concert Performance Through Historic Auralisation of Notre-Dame Cathedral. Intl Conf 3D Audio (I3DA), Sep 2021, Virtual, Italy. 10.1109/I3DA48870.2021.9610849 . hal-03371681

\section{HAL Id: hal-03371681 \\ https://hal.science/hal-03371681}

Submitted on 8 Oct 2021

HAL is a multi-disciplinary open access archive for the deposit and dissemination of scientific research documents, whether they are published or not. The documents may come from teaching and research institutions in France or abroad, or from public or private research centers.
L'archive ouverte pluridisciplinaire HAL, est destinée au dépôt et à la diffusion de documents scientifiques de niveau recherche, publiés ou non, émanant des établissements d'enseignement et de recherche français ou étrangers, des laboratoires publics ou privés. 


\title{
La Vierge 2020 : Reconstructing a Virtual Concert Performance Through Historic Auralisation of Notre-Dame Cathedral
}

\author{
(Invited Paper) \\ Brian F.G. Katz and David Poirier-Quinot \\ Institut d'Alembert, Sorbonne Université, CNRS \\ Paris, France \\ \{brian.katz/david.poirier-quinot $\} @$ sorbonne-universite.fr \\ Jean-Marc Lyzwa \\ Conservatoire National Supérieur de Musique et de Danse de Paris \\ Paris, France \\ jmlyzwa@cnsmdp.fr
}

\begin{abstract}
In honour of the International Year of Sound and for the 1 year memorial of the Notre-Dame cathedral fire, a team of researchers and sound engineers created a virtual reconstruction of a concert in the cathedral, using close-mic recordings made on 24-April-2013 of a performance of La Vierge by Jules Massenet. This reconstruction was carried out during the period of strict COVID-19 confinement. With 83 musicians, 6 singers and a 160person choir spatially distributed throughout the cathedral, the original performance offered a spatial composition highlighting the complex acoustics and interactions between source and listener positions. Individual tracks were convolved with spatial room impulse responses, created from a calibrated geometrical acoustic simulation. Several listening positions were binaurally rendered, along with an artistic mix created by a sound engineer, offering a unique 3d-audio experience approaching the reality of the moment in the past. Distributed on-line, the website presenting this virtual reconstruction has been visited from users around the world. A listener opinion survey was included on the website. This paper presents an overview of the source material, the production workflow, and the challenges of realising such a production during confinement. Finally, an overview of visitor statistics and survey results is presented, providing insight into the reception of the virtual recreation and the interest towards future productions.
\end{abstract}

Index Terms-Heritage acoustics, room acoustics, auralization

\section{INTRODUCTION}

In honour of the International Year of Sound (sound2020.org) and for the 1 year memorial of the Cathedral of Notre-Dame de Paris fire, a team of researchers and sound engineers created a virtual reconstruction of a performance recording made in the cathedral, recreating the monumental acoustics and the event. As part of the celebrations of the 850 year anniversary of the construction of Notre-Dame de Paris, on 24-April-2013 the cathedral welcomed a performance of La Vierge. To share this performance with those who could not attend, and to honor the cathedral, damaged by the fire on 15-Apr-2019, acoustic

Funding has been provided by the European Union's Joint Programming Initiative on Cultural Heritage project PHE (The Past Has Ears, phe.pasthasears.eu), the French project PHEND (The Past Has Ears at Notre-Dame, Grant No. ANR-20-CE38-0014, phend.pasthasears.eu), and the Chantier Scientifique CNRS/MC Notre-Dame. researchers and sound engineers have taken these recordings and an acoustical 3D model of Notre-Dame, created from measurements, to recreate the concert from several listening positions; the place of the conductor, in the first row, middle audience, and rear of the cathedral, offering a unique $3 \mathrm{~d}$-audio experience approaching the reality of the moment in the past. This approach offers the possibility of realistic listening at a given position, which is of course not necessarily the ideal seat, nor is it comparable to the type of artistic mix we have grown accustomed to with broadcast or CD material which provides often a heightened readability and understanding of the work when compared to what is physically possible.

\section{ConteXt}

\section{A. The Acoustics}

Notre-Dame de Paris is among the most well-known worship spaces in the world. Its large volume, in combination with a relatively bare stone construction and marble floor, lead to rather long reverberation times. On the evening of 13-April2015, almost 4 years to the day before the 2019 fire, a series of acoustic measurements were carried out following a small concert rehearsal. Subsequent to the fire, access was granted to the reconstruction site and acoustic measurements were carried on 30-June-2020. The full details of the measurement method, results, and comparisons with measurements made a few decades earlier can be found in [1], [2].

Results from these measurements can be represented by the calculated reverberation time. Figure 1 summarizes these results for three different measurements carried out in the Cathedral of Notre-Dame de Paris over more than 3 decades.

Further analysis of the energy decay curves showed a nonlinear decay typically associated with coupled volume acoustic conditions. This would seem reasonable considering the large and complex volume of the cathedral. These decay curves were analysed and the characteristic bending point in the decay were identified. Results of this analysis are shown in Fig. 2, highlighting the differences in early versus late reverberation times.

While the acoustics appears significantly altered since the fire, this is not a subject of the current study. 


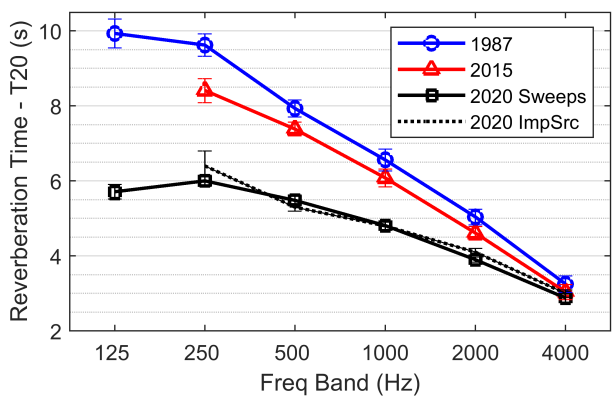

Fig. 1. Mean reverberation time (T20) over omnidirectional microphones with standard error bars. 2020 results show those for both sweep stimuli and impulse source gun-shots. (From [1].)
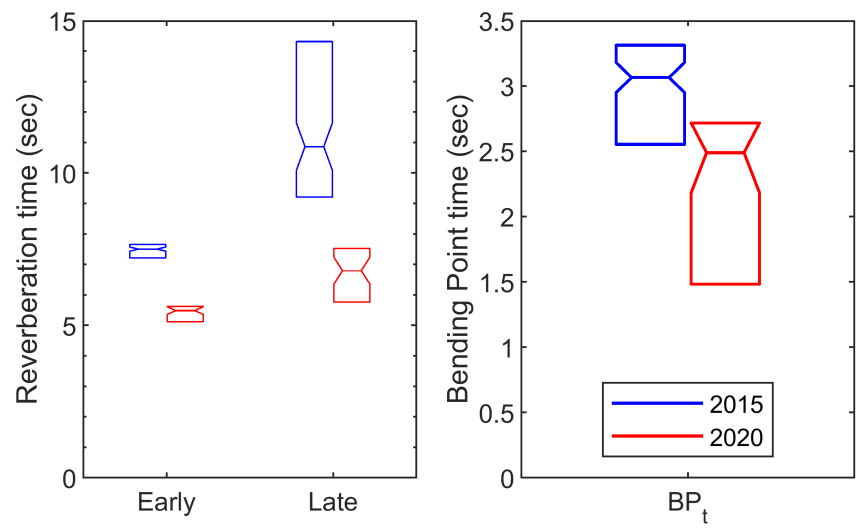

Fig. 2. Double-slope decay analysis distribution in the $500 \mathrm{~Hz}$-octave band (left) Early and Late reverberation times and (right) relative time $\left(B P_{t}\right)$ of the identified bending point in the decay curves (see [3] for parameter details). Notched boxplots show the median, $95 \%$ confidence interval, 25th and 75th percentiles of the data spread. (From [1].)

\section{B. In Music History}

For more than 850 years, Notre-Dame de Paris has been the sounding box for the city's sacred music. ${ }^{1}$ Built to amplify the sacred word, spoken or sung, the Cathedral of NotreDame de Paris is a multiform sound space with the clamor of pilgrims circulating in the ambulatory and the chanting of services protected by the choir's enclosure. The Schola singing the mass and the humming of the low masses in the radiant chapels used to coexist until today, when before the fire, the call to silence for noisy visitors, the sound of the masses, the bursts of sound from the great organs and the concerts alternated.

Soon after its construction at the end of the 12th century, this Gothic cathedral became the emblematic place of musical creation in Europe, which historians call the "École de NotreDame". Documents testify to the intense musical activity during this period and it is possible to think that the spectacular development of this Parisian polyphony coincided with the organization of the liturgy in the new acoustic space inaugu-

\footnotetext{
${ }^{1}$ This section is an excerpt from the text provided on the project website [4] by Frédéric Billiet, Professeur en musique médiévale, Sorbonne Université.
}

rated in $1182^{2}$ Luckily we have the Treatise of Anonymous $\mathrm{IV}^{3}$, in which a witness to events describes musical practices circa 1275 in the choir of this cathedral where the sound of the organum and semi-improvised conductus could rise, towards the apse, before being noted in various manuscripts which testify to the richness of the Magnus liber organi (see [7], followed by other volumes). During the period known as Ars Antiqua, i.e. the transition period between the École de Notre-Dame and Ars Nova (1320), the cathedral gradually lost its musical supremacy, although the chapter maintained the number of altar boys recruited for the Mastery and financed the construction of the choir organs (circa 1334) and the organ loft (circa 1415).

Over the centuries, the Gregorian chant remains the most important practice. The melodies escape from the closed choir mixed with the sounds of the organ, the bells, and sometimes with complex polyphonic works of the FrancoFlemish counterpoint (15th century). The history of music will remember the names of great masters and composers such as Antoine Brumel (†1513), André Campra (†1744), Jean-François Lalouette $(\dagger 1728)$, or Jean-François Lesueur $(\dagger 1837)$, who, after the revolutionary period, composed the famous March of the Coronation, for Napoleon's entry into the cathedral in 1804, and various pieces for the Coronation Mass. That was a great opportunity to hear the organ built by François-Henri Clicquot (1783), restored afterwards by Aristide Cavaillé-Coll, while Viollet-le-Duc proceeded with the monumental restoration of the building.

The vaults heard everything during the 20th century, starting with the concerts of the greatest French organists and the most diverse musical groups, not forgetting the repertory of the liturgy. "In 1990, Cardinal Lustiger asked Jean-Michel Dieuaide to rethink the cathedral's permanent musical system. This reflection was carried out in collaboration with Guillaume Deslandres, who founded the association Musique Sacrée à Notre-Dame de Paris (MSNDP), of which he became the first director. (...). As in its early days, music continues to play a considerable part in the influence of Cathedral of NotreDame de Paris. The weekly organ auditions, the monthly organ recitals, the concerts given by the Maitrise (choir of the cathedral), all testify to the high standards and excellence to which all those involved in music at Notre-Dame today apply" 4 .

\section{Massenet's La Vierge}

Passed on to posterity for the meditation of Thaïs or the letters aria from Werther, the figure of Massenet (1842-1912) remains attached to that of the French opera before Debussy's

\footnotetext{
${ }^{2}$ The main documents evoking this practice in organo, vel triplo vel quadruplo were published in 1932 [5]. See more recently [6].

${ }^{3}$ Anonymous IV points to two instances of Perotin's organum quadruplum - Sederunt principes and Viderunt omnes - in which the rhythmic swirling and interweaving of vocal parts make for a strikingly original sound-world.

${ }^{4}$ See www.notredamedeparis.fr:"L'école épiscopale".
} 
Pelléas et Mélisande. ${ }^{5}$ Massenet also cultivated the oratorio, as evidenced by Marie-Madeleine (1873), Eve (1875), La Vierge (1880), and La Terre promise (1900). The distance between opera and oratorio, or between sacred and profane love, is tenuous at the end of the 19th century, which saw the birth of Franck's Les Beatitudes (1879) and Gounod's La Redemption (1882). It is therefore not surprising that Massenet's work was premiered at the Paris Opera on 22-May-1880, during the first of the Historical Concerts of the new director Vaucorbeil, alongside works by Lully, Rameau, Gluck, and Grétry.

Massenet, a pupil of Ambroise Thomas, who won the first Prix de Rome in 1863 and was appointed professor of composition at the Paris Conservatoire in 1878, had made a name for himself with the orientalist opera Le Roi de Lahore (1877) when he tackled his oratorio La Vierge, a figure he would find again in the lyrical miracle Le Jongleur de NotreDame (1902).

In 1875, Massenet met the young poet Charles Grandmougin who wrote for him the booklet of this sacred legend in four parts: The Annunciation, The Marriage at Cana, Good Friday, and The Assumption. He completed his score in August of 1879. The four parts retrace four key moments in the life of the Virgin Mary, contrasting situations exploited by Massenet. More dramatic, but also shorter, the two central parts draw on the operatic side with grandiose choirs (No. 5: Chour $d u$ festin), funerals (No. 10: c'est Jésus qu'on mène au trépas), but also moments of choral recitation (Jésus s'est arrêté) reminding of Berlioz's (1803-1869) Roméo et Juliette ouverture. The two extremes would rather lean towards Berlioz's L'Enfance $d u$ Christ, with this initial, almost monodic Pastoral. The fourth scene remains the one that our 21 st-century sensibilities understand best: the instrumental Andante religioso (No. 10: Last Sleep of the Virgin) is taken up again in the Chour des Anges with a wonderful harp accompaniment, while the ecstasy of La Vierge, Infinite Dream, Divine Ecstasy, literally transports the listener to the afterlife before the Magnificat closes the ensemble.

\section{Review of the 24-April-2013 performance}

The following is an excerpt translation of the concert performance review by Patrice Imbaud:

Sacred legend in four scenes, for soloists, choirs, and orchestra. Libretto by Charles Grandmougin. Norah Amsellem, soprano. Maitrise de Notre-Dame de Paris, French Army Choir, Sotto Voce Children's Choir. Orchestre du Conservatoire de Paris, dir. Patrick Fournillier.

Presented as part of the celebration of the 850th anniversary of Cathedral of Notre-Dame de Paris, La Vierge, by Jules Massenet (1842-1912) is a rare work, first performed in 1880 at the Paris Opera, under the direction of the composer. At its premiere, initially scheduled at Notre-Dame, this work was

\footnotetext{
${ }^{5}$ This section is an excerpt from the text provided on the project website [4] by Lucie Kayas, Doctor in musicology, Professor of musical culture at the CNSMDP
}

highly regarded and received a rather cold reception, due to the heavy program, which presented works by many other composers together... Sacred legend in four scenes, from a text by Charles Grandmougin, evoking the main episodes of the Virgin Mary's life through the biblical accounts of the Annunciation, the Wedding at Cana, Good Friday and the Assumption, this oratorio, with its terribly human accents in the expression of feelings, emancipates itself from the liturgy to become a true concert piece. One finds in it one of the great feminine figures of Massenet's imagination, with its joys, its rages, its weaknesses, its pain; which did not fail to provide subject to criticism, some reproaching Massenet for having composed too theatrical a music on such a mystical subject... A music, indeed, full of dramatic effects, colors, rhythm, different climates sometimes very surprising, like the very profane Galilean dance. A brilliant work by its melodic line and the richness of its orchestration, grandiose and moving, served by a stage of more than 250 musicians, placed under the direction of Patrick Fournillier, undisputed specialist of the work of Jules Massenet, who leads from hand to hand, from end to end, with precision, commitment, and delicacy. Norah Amsellem, too often absent from the French stages, although she has had an international career for several years, knew how to give the Virgin all her humanity, through her remarkable singing, her perfect diction and her stage presence.

\section{OVERVIEW}

The creation of this virtual concert reconstruction followed several stages : recording, acoustic simulation \& auralization, and mixing. Each of these elements is described briefly here. Links to more detailed presentations of each element are provided.

\section{A. Concert recording}

This recording of La Vierge by Jules Massenet was made on 24-April-2013 in the Cathedral of Notre-Dame de Paris. The work consists of an orchestra of 83 musicians, 6 solo singers and 2 choirs comprising 160 choristers. For this production, the performance was arranged with the objective of spatially staging the performers (see Fig. 3), highlighting the unique acoustics of Notre-Dame and the interactions between the different positions of the groups and the listener:

- The orchestra and the main choir were positioned in front of the transept crossing. The orchestra was raised on a 2-level stage. The choir was located on a 5-storey tier in the rear extension of the orchestra.

- The children's choir intervened in the cathedral choir at the start of the piece, behind the transept crossing. It was located $35.7 \mathrm{~m}$ from the conductor. The children's choir was not visible to the public at this location. A small ensemble, consisting of two harps, a positive organ and 


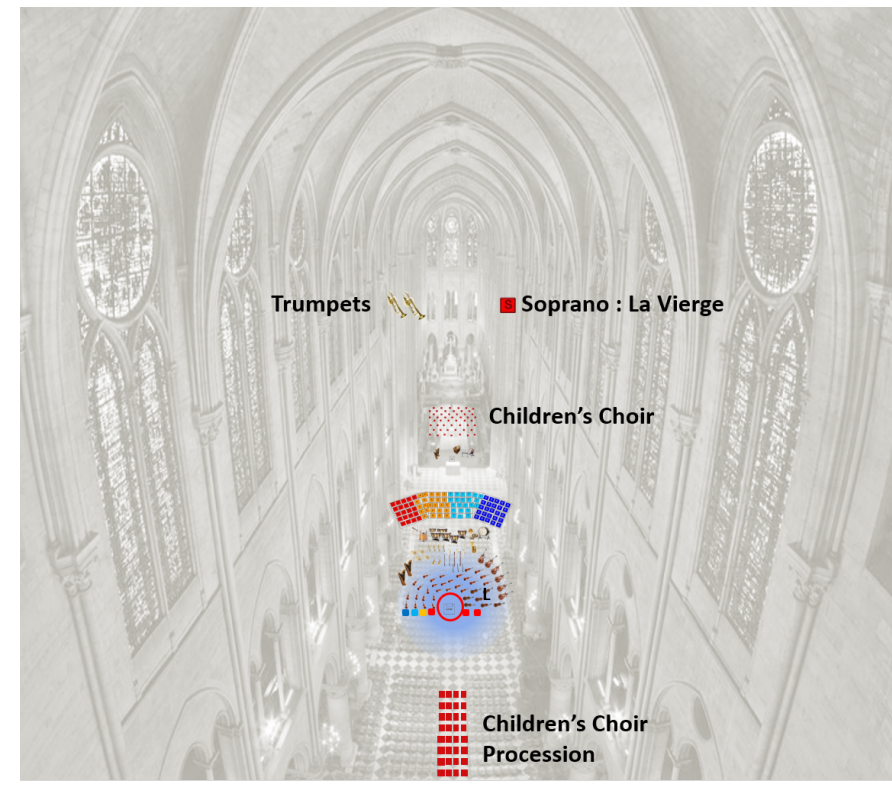

Fig. 3. 3D view within the cathedral highlighting the positions of the various musicians during the performance and the $(\bigcirc)$ conductor's position. Note the position of the trumpets and Soprano in the gallery, on the far side of the transept, and the children's choir principal position at the far end of the nave and for their procession down the audience aisle.

a small percussion ensemble was positioned in front of the children's choir.

- The children's choir took part in a procession behind and among the audience in the 4th scene.

- Two trumpeters played in the 3rd scene on the Tribune on the garden side of the transept (distance: $34 \mathrm{~m}$ from the conductor).

- La Vierge (soprano) intervened in the finale from the Tribune on the courtyard side of the transept (distance $33.4 \mathrm{~m}$ from the conductor).

A total of 56 microphones (main system, spot-mics, and ambiance) were deployed in order to capture this work. Full details of the recording setup are available in the recording documentation report [8].

\section{B. Acoustic simulation \& Auralization}

A computer room acoustic model of the Cathedral of Notre-Dame de Paris was created, as shown in Fig. 4. The geometry of the cathedral was determined from a 3D laser scan point cloud and architectural plans and sections. To each element of the model was assigned a specific acoustic material, related to the acoustic absorption and scattering properties, representative of the physical surface's roughness.

This geometrical acoustics model was then fine-tuned through calibration (see Fig. 5) to match the acoustic parameters obtained from measurements [9]. Beyond acoustic parameter comparisons, this calibration was further evaluated through perceptual comparisons [10].

Within the calibrated model, each soloist and/or section of the orchestra which were recorded on a separate track were defined as an acoustic source, with a corresponding

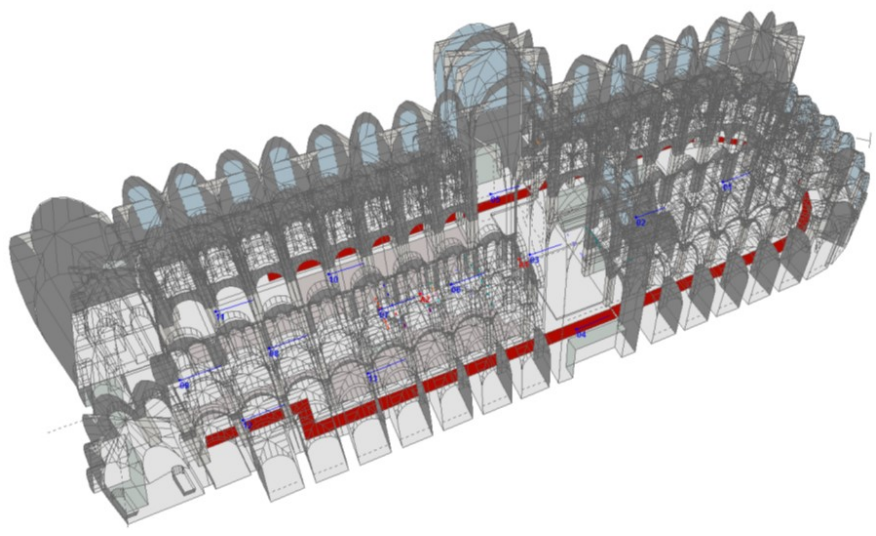

Fig. 4. View of the 3D Geometrical Acoustics model of Notre-Dame.
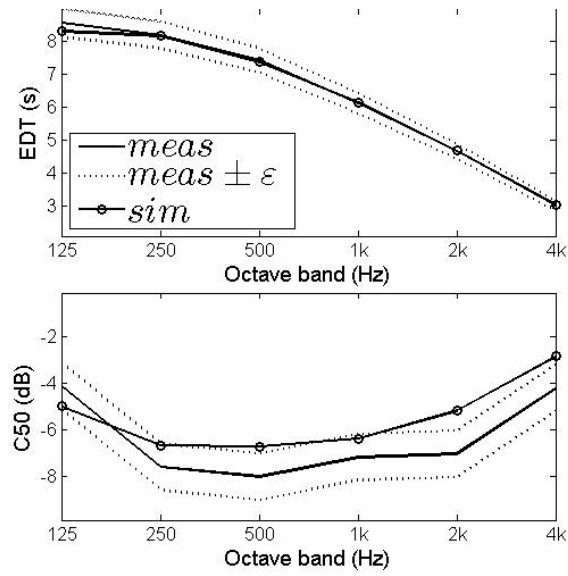

Fig. 5. Comparison of room acoustic parameters EDT and C50 calculated on the measured ( \pm JND, Just-Noticeable Difference for each acoustic parameter) and simulated RIRs highlighting the quality of the calibration.

representative directivity pattern. Virtual listener locations were then defined, and the acoustic propagation characteristics of the cathedral, for each source-receiver combination, were simulated using a geometrical acoustics prediction software (CATT-Acoustic v9/TUCT2 ${ }^{6}$ ), a process taking several weeks considering the large number of sources and complex room geometry. This calculation produced Room Impulse Responses (RIRs) for each source-receiver combination.

With these RIR results, which are represented as signal filters, each recorded track is processed via convolution with the corresponding filter, thereby placing the recorded performance in the virtual room simulation, a process called auralization as the audio parallel to visualization. Details of this procedure can be found in [11].

In virtual acoustic renderings, the goal is to recreate the spatial acoustic cues that we as humans use to "decode" the soundscape around us. Such cues are represented by what is termed the Head-Related Transfer Function (HRTF), and like the RIR of the cathedral, it is specific to the geometry, here being an individual's head, torso, and especially ear shape.

\footnotetext{
${ }^{6}$ www.catt.se
} 
As it was not possible to render this concert performance individually for every listener, it was necessary to choose the HRTF, or the "ears", of an individual which all spectators will listen through. As a subject of active study by the acoustic research team, numerous listening tests have been carried out previously comparing how we hear through other people's ears. For this project, we selected the most often best rated set of ears from our most recent study. This was HRTF number 1032 from the LISTEN HRTF database [12], [13]. This HRTF was therefore incorporated into the geometrical acoustics prediction software as a directional receiver, looking directly forward towards the choir section of the cathedral. For the cases when ambiance recordings were spatialized directly through binaural processing (see further discussion in Section III-D), the same HRTF was used to ensure spatial perception coherence.

\section{Mixing / Post-processing}

1) 2013 Artistic production mix: This production opted for a sound recording aimed at reproducing all the complexity of this spatial musical scene: we wanted to place the listeners at the conductor position, while immersing them in the unique acoustics of the cathedral. We chose this position as interesting because it allows the conductor to establish, control, adapt, qualify, and correct the instrumental balance of the work very precisely according to the acoustics.

The recording described in Section III-A was intended for a broadcast production by the CNSMDP which reproduced this staging as faithfully as possible. The work was produced in three formats:

- Binaural stereo

- Transaural stereo (binaural 3D audio for 2 speakers) using $\operatorname{Transpan}^{7}$ [14], [15]

- 5.1 (enhanced with transaural for 3D)

The stereo productions (i.e. binaural \& transaural stereo) are available on-line ${ }^{8}$. The 5.1 format production included transaural elements to create a 3D mix using Transpan, introducing frontal L-R and rear Ls-Rs transaural streams.

This mix was realized in three stages:

1) The first stage was to achieve a realistic balance of all the different microphone tracks:

- The main capture system: an array of 5 omnidirectional microphones (DPA 4041) placed above the conductor captured a global vision of the sound scene.

- The auxiliary microphones : positioned near the sources, captured each section of the orchestra, soloists and choirs, which they reinforce relative to the main system recording.

2) The second stage consisted in integrating the natural acoustics of the recording space, recreating the different sound planes, such as placing the strings in front of the woodwinds, the woodwinds in front of the brass, etc.

${ }^{7}$ alexisbaskind.net/transpan

${ }^{8}$ www.conservatoiredeparis.fr/fr/medias/recherche
Each auxiliary microphone was adjusted in time with respect to the main system as a function of the distance separating it from the latter. Adjustment of these delays makes it possible to emphasize and stabilize the different sound planes.

Finally, the ambient array was, made up of 8 omnidirectional microphones (DPA 4006) located on either side of the central nave in pairs at $8 \mathrm{~m}$ intervals from the orchestra, captured the acoustics and sound color of the cathedral at different positions. These elements were mixed with the other tracks to give the listener the feeling of being inside the cathedral.

3) From this mixing base, we carried out fine-tuning in accordance with the indications of the musical score in order to support or move away a particular musician or singer according to the nuances described by the composer. The objective of the mix was to bring the realism of the recorded environment while keeping the maximum musical readability, to allow the work to be heard inside the space of the recording with the strictest respect for compositional intention.

2) 2020 Virtual reconstruction mix: The approach to the virtual reconstruction mix was different from the artistic mix described in Section III-C1. For this production, the mix was based on processing the auxiliary microphones with the synthesised natural acoustics of the cathedral. We therefore started with the 2013 recording using only the auxiliary microphones, the microphones closest to the sources. Due to their proximity, these microphones predominantly pick up the direct sound of the instruments, voices or choirs they point to.

Mixing: The relative levels and the balance of all the microphones are adapted in order to obtain a harmonious balance between the different instrumental and vocal ratios while respecting the balance desired by the conductor and described by the score. These subtle adjustments are the result of a good knowledge and expertise of the acoustics of the place, having to this date recorded more than twenty musical works in Notre-Dame de Paris.

The recorded tracks at the conductor's position are used to provide a reference for adjusting levels at the reconstructed conductor position. Using those established levels, the sound is then rendered at the other listening positions, without modifying any levels, in order to maintain the same "natural" balance across the orchestra.

Each track was processed with the BRIR filter corresponding to its position in relation to the virtual listener. These BRIRs were managed with the Pyramix workstation (Merging) and processed using Aalto University's SPARTA MutiConv ${ }^{9}$ [16], a plug-in which implements the convolution of each microphone signal with the respective BRIR filter.

This mixing is an unusual approach for this type of musical production where, in general, it is advisable to privilege the precision and clarity of restitution of the various instruments and singers, providing high readability. In contrast, here we

\footnotetext{
${ }^{9}$ research.spa.aalto.fi/projects/sparta_vsts
} 
want to give the listener an extremely realistic listening sensation of a complex soundstage at a specific location in the recording venue. The balance sought here was to give the listener the immersive sensations they would have had in the cathedral on the day of the concert, for each of the 4 positions chosen. The balance perceived by the listener will be modified according to their listening position in the cathedral, with an expectation of loss of precision as they move further away from the orchestra.

\section{Limitations}

There were many recognized limitations to this production. Some of the most pertinent limitations are discussed below.

As the sound recording was carried out in the very reverberant acoustics of the cathedral and not in an anechoic chamber, each microphone track was still somewhat impacted by the acoustics of the cathedral. Each microphone also picked up to some degree neighboring instruments, in addition to the intended instrument it was directed at. The main drawback of this approach was that it resulted in a certain spatial blurring, an imprecision in the localization of certain instruments or instrument groups as they were reproduced over several virtual sources. Due to the imperfect recording conditions of the concert of microphones capturing other instruments at times, fine adjustments were attempted to remove (mute) them when possible. However, when both instruments were playing, this cross-talk between recorded tracks could not be removed. The result was that at times some instruments may appear to come from multiple positions within the orchestra, somewhat blurring the spatial precision of the virtual concert. One can also feel at times phase effects which can be unpleasant on certain passages. In addition, there were a few moments when musicians may have slightly bumped their microphones, or rustled their scores, which of course was included in the production.

While a significant effort was made to get close proximity recording of all performers, this was not always possible. For example, the procession of the children's choir in the 4th scene, when the chorus slowly approaches from behind the conductor, was only captured with the ambiance microphones. As these ambiance recordings include the room acoustics, they were not processed through the virtual acoustic model, as this would have produced a double reverberation effect. To integrate these elements into the virtual concert, they have been binaurally rendered directly using Sorbonne University's Anaglyph $^{10}$ [17], a binaural rendering plug-in, placing them at the performers' approximate positions relative to the listener during the performance.

A hard-coded binaural rendering approach was employed, fixing both the head/ear morphology of the virtual listener, as well as its orientation. The use of a non-individual HRTF can lead to degradations of various perceptions, including but not limited to spatial aspects [18]. An alternative would be to rely on dynamic decoding over headphones, which was previously

10 anaglyph.dalembert.upmc.fr used for the audio-visual virtual fly-through of the cathedral [11], with only a short extract of the concert. While the spatial precision of such real-time Virtual Reality (VR) presentation is currently limited to 1st or 2nd-order Ambisonics, depending on the streaming platform, the ability to move one's head (best when using a device with gyroscope tracking) really benefits immersion in the virtual cathedral.

As a final point, we would like to indicate that part of the simulation work, and the entirety of the mixing and creation of the website, were carried out during the 1st COVID-19 confinement period in France: working on mostly portable and home machines, with all their limitations, being much less efficient and more limited compared to the 2013 production carried out in a professional studio.

\section{PubliC Diffusion}

The production was made available on the 2020 anniversary commemoration of the fire on the website of the Acoustics Working Group of the Chantier Scientifique CNRS/MC NotreDame [4], including a brief description of various elements and the inclusion of a questionnaire. The 1 st set of audio examples provided a 5 min $31 \mathrm{~s}$ montage of the production for each of the various listening positions, including an equivalent extract from the 2013 artistic mix in order to provide an element of comparison built on a more conventional approach to musical productions (see Fig. 6). This was followed by four full movements highlighting certain notable elements. Finally, the 3rd audio set contained the full $1 \mathrm{~h} 23 \mathrm{~min}$ concert, for the same ensemble of listening configurations.

The project was included in the International Year of Sound 2020-2021 program, in the section "Special Projects" due to it lacking a specific performance date. The publication/release was also announced on various social media platforms.

\section{A. Website access statistics}

As of 15-May-2021, since the opening of the site, it has been visited $\approx 4800$ times (Google Analytics), with $\approx 3900$ visits occurring in the month of April 2020. However, taking into account bots and search engines, we note from the analytics that just 453 of these visits explored the page for more than $3 \mathrm{~min}$, and 194 for more than $1 \mathrm{~h}$. It should also be noted that the production was available for download from the site in the event of poor internet connection, while also accessible directly via the Mediatheque of the Conservatoire National

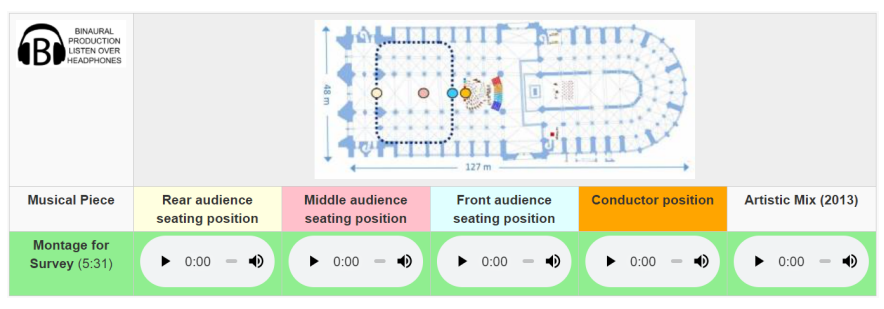

Fig. 6. Website player frame with audio extracts, visual representation of the listening positions for use with the questionnaire, and indication to listen over headphones. 

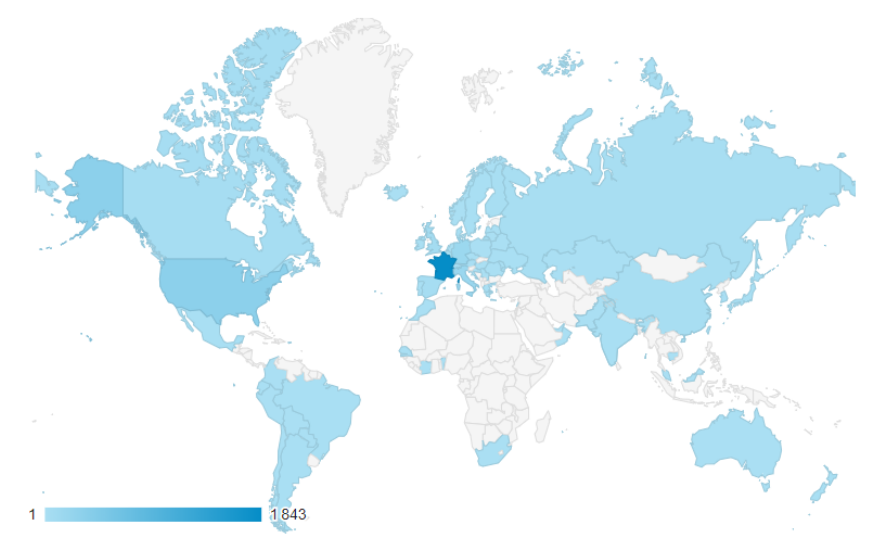

Fig. 7. Geographic distribution of website connections to the production homepage.

Supérieur de Musique et de Danse de Paris, which hosted the audio files. No statistics were recorded for these access options.

Examining the geographical distribution of visits, $61 \%$ were in France, the host country for the project. The remaining geographical origins spanned Europe, Australasia, and the Americas, with a few connections from the African continent (see Fig. 7).

To provide some indication of technologies employed by visits, as this can help developers, producers, and distributors anticipate likely platforms, we note that $66 \%$ of visits were from "desktop" computers, $29 \%$ from "mobile", and $5 \%$ classified as "tablet". Of mobile and tablet devices, $49 \%$ were via Apple's iOS. Concerning browser technology, $38 \%$ of visits used the Chrome browser, $28 \%$ Safari, $17 \%$ Firefox, with other browsers individually never representing more than $6 \%$.

\section{B. Questionnaire}

The questionnaire (Google Forms) allowed us to gather more information, and more importantly, impressions of the spatial audio reconstruction from the public. Of those individuals who visited and listened to the production, 31 completed the on-line survey, representing $\approx 7 \%$ of the population who visited the site for more than $3 \mathrm{~min}$.

1) Background/situational data: As with the website statistics, several connection related information were gathered which may prove generally useful. To begin with, internet connections occurred 5 times more frequently over WiFi than either wired connections or GSM. Regarding listening devices, $67 \%$ listened over wired headphones, $17 \%$ over wireless headphones, and the remaining evenly split between activenoise control headphones and loudspeakers, despite indications to listen over headphones. On a scale from 1 to 5 , with 5 being best, participants rated their headphones with an average quality ( \pm standard deviation) of $3.5 \pm 0.9$ and the background noise level of their listening environment $3.9 \pm 0.8$.

The range of ages of respondent covered a large spectra, from under 18 to over 75 years old. As shown in Fig. 8, the

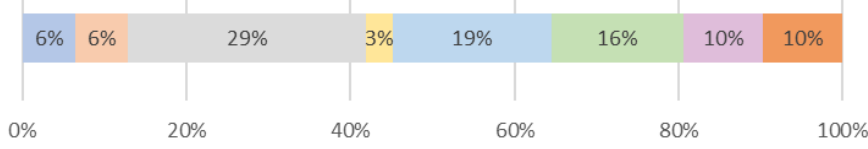

m Under $18=18$ to $24=25$ to $34=35$ to $44=45$ to $54=55$ to $64 \| 65$ to $74 \backsim 75$ and up

Fig. 8. Age range of respondents to the questionnaire.

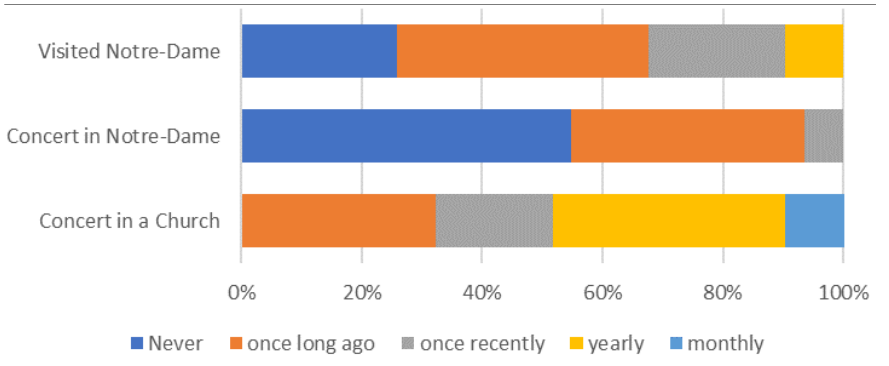

Room acoustic simulations

Binaural rendering

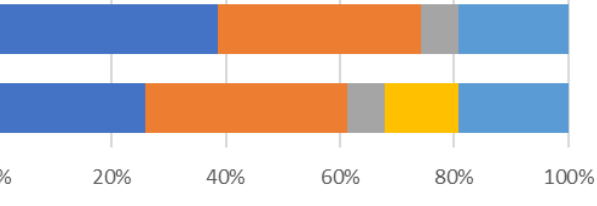

Not at all $\quad$ Slightly $\quad$ Monthly $\quad$ Weekly $\quad$ My job

Fig. 9. Respondents concert and Notre-Dame de Paris visit (top) frequenting rates and (bottom) familiarity with room acoustics simulations and binaural rendering.

largest represented age group was 25 to 34 , followed by 45 to 54 years old.

Regarding personal experience, respondents were asked about their frequentation habits regarding listening to concert performances in churches/cathedrals, specifically in NotreDame, and also concerning visitation of Notre-Dame de Paris. As reported in Fig. 9, the clear majority of them had little to no experience of listening to a concert within NotreDame, though all had visited the cathedral at least once. The audience experience supports the intention of the production in bringing a new public into the cathedral though virtual acoustic reconstructions.

Due to the nature of the production, it was also of interest to know what previous experience respondents had with room acoustic simulations and binaural rendering. Results show a range of familiarity, from none to professional experience, with the latter category representing $\approx 20 \%$. This could be due to the association of the event with the International Year of Sound, as well as its dissemination on various special interest social media channels.

2) Production specific data: With the intention of the production to bring the public into the virtual performance reconstruction, while also highlighting the variations in its acoustics as a function of position, several questions were posed regarding appreciation of the production. Specifically, "How noticeable were the effects of changing position?" and 


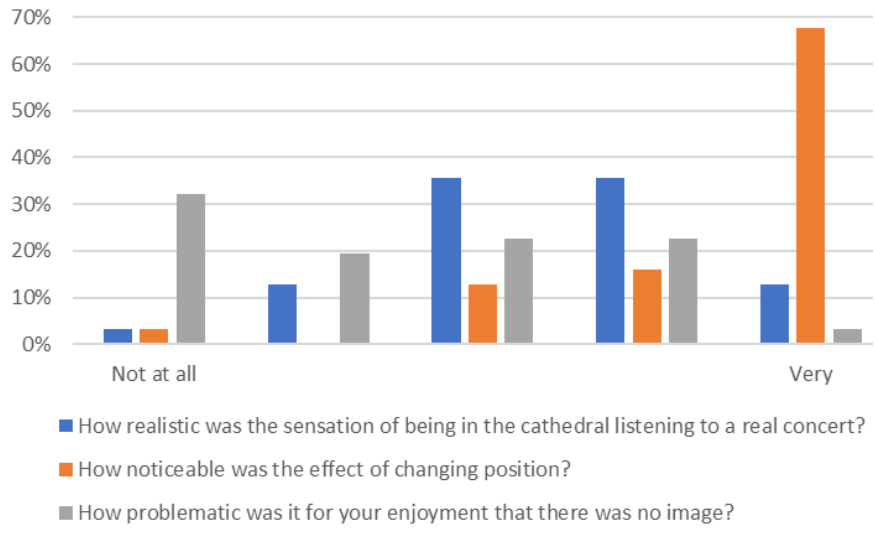

Fig. 10. Respondents perception and sensitivity to reproduction conditions.

"Did the virtual reconstruction sound like listening to a live concert?". Results, summarized in Fig. 10, show that for the vast majority of people the change in position was very audible and that the reconstruction was quite realistic, though there is room for improvement.

A final question concerned the potential negative impact of a lack of visuals, as this production was audio only, the equivalent of a live immersive radio event. Responses for this question show that respondents found the absence of image generally, though not extremely, problematic. We note that our previous virtual reconstruction effort for this same project included visual $360^{\circ}$ VR rendering in conjunction with the spatialized audio [11]. However, it should be noted that this previous audio-visual production contained only a $2 \mathrm{~min}$ extract of the same concert. It was not imagined that the general public would be interested, equipped, or accepting of spending potentially over an hour listening to this production in VR, at least without significant effort in creating new and more lively visuals.

In order to have a sense of global appreciation, a ranking regarding quality was included. As shown in Fig. 11, the rear position tended to have lower ratings while, among the physically realistic positions, the conductor's position was generally viewed as having higher quality. The artistic mix, which presented a sound scene that was not limited to the physical reality of sound propagation, was generally highly ranked. However, in addition to the general trends, it is important to note that each of the five conditions was ranked highest by at least one respondent, and vice versa, each was also ranked lowest by at least one respondent. This lack of general agreement reinforces the notion that, as individuals, each listener has different expectations and preferences with regards to their preferred soundscape configuration.

This variability has been similarly observed for example in seating preferences in concert halls, where preferences are determined by multiple factors and individual interests, such as clear distinction of separate instruments versus a general blending across musicians and with the hall's acoustics. This is equally seen in opera and cinema where the addition of visual elements is equally important, with preferences over

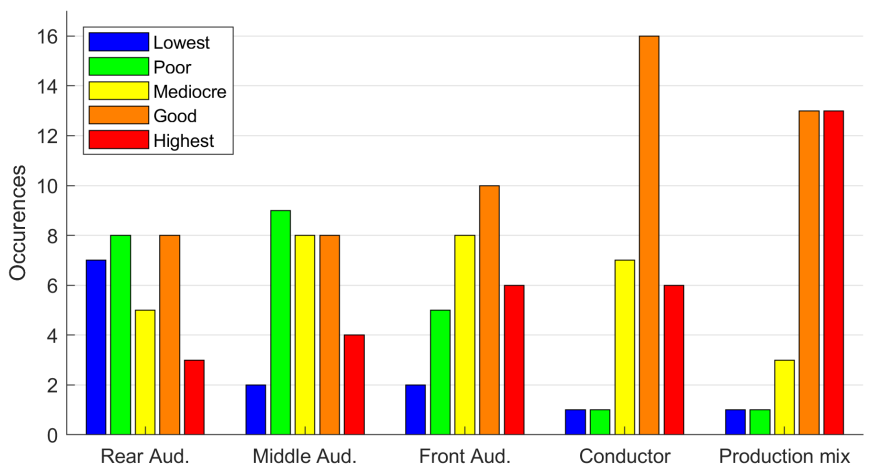

Fig. 11. Histogram of quality judgement ratings for the different positions, including the artistic mix.

immersion versus observability of the attending public can be found.

The final questions concerned future productions. Respondents were overwhelmingly positive about interest in future virtual productions within Notre-Dame de Paris, with $87 \%$ in favor. With an eye to future potential, we also asked about interest in live-streaming of events from the virtual cathedral, which was also viewed positively, with $84 \%$ in favor.

\section{CONCLUSION}

We have presented an overview of the various elements involved in the creation of a virtual concert reconstruction within a numerical model of the Cathedral of Notre-Dame de Paris, using a multitrack recording of a large orchestral production of La Vierge, oratorio by Jules Massenet. The historical importance of Notre-Dame de Paris as well as the context of the composer and the composition were provided. The technical conditions of the 2013 concert recording and original resulting spatial audio production were described. This was contrasted with the various technical details employed to carry out the virtual concert reconstruction using the same original recording material. The production's intent was to highlight the spatial nature of both the concert and the different perceptions of the performance with the cathedral's voluminous expanse.

Following the overview of historical, technical, and audio engineering aspects, data collected over 13 months of availability on-line, including a listener questionnaire provided along side the audio production material were presented. In general, the production was experienced by listeners of practically all ages and from around the world. While all respondents to the questionnaire had visited Notre-Dame before, they had listened at most to a single concert in the cathedral previously. As such, the audience coincided with the projects intention, exposing a relatively naive public to a $3 \mathrm{D}$ acoustic concert performance in the cathedral, currently under restoration after the fire in April 2019.

With the general positive opinion of the production, and the encouragement by respondent's to continue such work, even extending to live concert performance in the virtual cathedral, this work is hopefully only the first of several which will be 
produced in the context of the Past Has Ears at Notre-Dame (PHEND) project, currently underway.

\section{ACKNOWLEDGMENT}

The team would like to thank the Rector-Priest of the Cathedral of Notre-Dame de Paris, Monsignor Patrick Chauvet, for granting us access to the Cathedral for both recordings and measurements. This production would not have been possible without the performers and musicians: Maitrise Notre-Dame de Paris, Lionel Sow, chef de chœur; Chœur de l'Armée française, Aurore Tillac, chef de chœur; Chœur d'Enfants Sotto Voce, Scott Alan Prouty, chef de chœur; Orchestre du Conservatoire de Paris, Quentin Hindley, chef assistant; Laura Holm, soprano; Charlotte Desaux, soprano; Caroline Michaud, mezzo; Benjamin Woh, ténor; Samuel Hasselhorn, baryton; Norah Amsellem, soprano; Patrick Fournillier, direction. We also thank Prof. Frédéric Billiet for contributing the section on the musicological context of the Cathedral of Notre-Dame de Paris.

\section{REFERENCES}

[1] B. F. G. Katz and A. Weber, "An acoustic survey of the Cathédrale Notre-Dame de Paris before and after the fire of 2019," Acoustics, vol. 2, SI: Historical Acoustics, pp. 791-802, Nov. 2020, doi:10.3390/acoustics2040044.

[2] B. N. Postma and B. F. G. Katz, "Acoustics of Notre-Dame Cathedral de Paris," in Intl Cong on Acoustics (ICA), (Buenos Aires), pp. 0269:1-10, Sept. 2016, (url).

[3] P. Luizard, B. F. G. Katz, and C. Guastavino, "Perceptual thresholds for realistic double-slope decay reverberation in large coupled spaces," J Acoust Soc Am, vol. 137, no. 75, pp. 75-84, 2015, doi:10.1121/1.4904515.

[4] Hearing the Past : A virtual immersive audio concert for the ears, (url),

[5] J. Handschin, "Zur geschichte von notre dame," Acta Musicologica, vol. 4, no. 1, pp. 5-17, 1932, (url).

[6] C. Wright, Music and Ceremony at Notre Dame of Paris, 500-1500. Cambridge: Cambridge University Press, 1989.

[7] E. H. Rosner, ed., Magnus liber organi de Notre-Dame de Paris. Les quadrupla et les tripla parisiens, vol. 1. Monaco: L'Oiseau-Lyre, 1993.

[8] J.-M. Lyzwa, "Compte-rendu de captation : La Vierge - Jules Massenet (1842-1912)," tech. rep., Conservatoire de Paris, 2013, (url).

[9] B. N. Postma and B. F. G. Katz, "Creation and calibration method of virtual acoustic models for historic auralizations," Virtual Reality, vol. 19, SI: Spatial Sound, pp. 161-180, 2015, doi:10.1007/s10055-0150275-3.

[10] B. N. Postma and B. F. G. Katz, "Perceptive and objective evaluation of calibrated room acoustic simulation auralizations," J Acoust Soc Am, vol. 140, pp. 4326-4337, Dec. 2016, doi:10.1121/1.4971422.

[11] B. N. Postma, D. Poirier-Quinot, J. Meyer, and B. F. G. Katz, "Virtual reality performance auralization in a calibrated model of Notre-Dame Cathedral," in Euroregio, (Porto), pp. 6:1-10, June 2016, (url).

[12] IRCAM LISTEN HRTF database, (url).

[13] O. Warusfel and G. Eckel, "LISTEN - Augmenting everyday environments through interactive soundscapes," in Workshop VR for Public Consumption, IEEE VR, (Chicago), 2004.

[14] A. Baskind, T. Carpentier, M. Noisternig, O. Warusfel, and J.-M. Lyzwa, "Binaural and transaural spatialization techniques in multichannel 5.1 production," in 27th Tonmeistertagung, VDT International Convention, (Köln, Germany), Nov. 2012, (url).

[15] J.-M. Lyzwa and A. Baskind, "Utilisation de techniques binaurales et transaurales en prises de son et en post-productions multicanales 5.1," in Conf Aud Eng Soc Brasil, (Sao Paolo), May 2009, (url).

[16] L. McCormack and A. Politis, "SPARTA \& COMPASS: Real-time implementations of linear and parametric spatial audio reproduction and processing methods," in AES Intl Conf on Immersive and Interactive Audio, (York), pp. EB111:1-12, Mar. 2019, (url).
[17] D. Poirier-Quinot and B. F. G. Katz, "The Anaglyph binaural audio engine," in Audio Eng Soc Conv 144, (Milan), pp. EB431:1-4, May 2018, (url).

[18] L. Simon, N. Zacharov, and B. F. G. Katz, "Perceptual attributes for the comparison of Head-Related Transfer Functions," J Acoust Soc Am, vol. 140, pp. 3623-3632, Nov. 2016, doi:10.1121/1.4966115. 